\title{
HPLC DETECTION OF SERUM AND URINARY PARAPHENYLENE DIAMINE (PPD) LEVEL AND ITS METABOLITES IN RELATION TO CARDIAC TOXICITY
}

\author{
Marwa Issak ${ }^{1}$, Mona M Ali, ${ }^{2}$, Sara Hamed Nasreldin Taha ${ }^{3}$, Fatma Ahmed \\ Mahmoud ${ }^{4}$,Hanan Alsayed Zaghla ${ }^{5}$, Mahmoud Khaled Nour ${ }^{6}$, Samah F. \\ Ibrahim ${ }^{7}$ Ahmed Samir Alsawii ${ }^{8}$, \\ ${ }^{1,3}$ Forensic Medicine and Clinical Toxicology, Faculty of Medicine, Cairo University, Egypt, ${ }^{7}$ \\ Princess Nourah bint Abdulrahman University, Riyadh, Saudi Arabia, Saudi Arabia, ${ }^{2}$ Taif \\ University, Saudi Arabia, ${ }^{4}$ Luxor International Hospital, ${ }^{5,6,8}$ Critical Care Medicine Cairo \\ University \\ Corresponding author: Marwa Issak: Missak1978@hotmail.com \\ Submit Date 2020-06-25 16:17:58 \\ Revise Date 2020-10-11 11:00:46 \\ Accept Date $\quad 2020-10-17$ 07:54:30
}

\section{ABSTRACT}

Hair dye poisoning is a significant emerging problem in Upper Egypt. The main component of hair dye causing toxicity is para-phenylenediamine (PPD). Ingestion of PPD could be accidental or suicidal. After oral intake, it is metabolized in the liver into N-mono(MAPPD) and N, $\mathrm{N}^{\prime}$ - diacetylated (DAPPD) metabolites. Tissue damage after PPD ingestions occurs due to increased free radical and oxidative stress that depletes tissue glutathione. Cardiac toxicity is a complication of PPD poisoning. It could be manifested by hypotension, different arrhythmia; besides, myocarditis and elevated cardiac biomarkers were also found. Serum and urinary levels of PPD, N-acetyl-p-phenylenediamine (MAPPD), and N--diacetylp-phenylenediamine (DAPPD) were measured by HPLC. A prospective cohort study was planned to determine the relationship between the serum and urinary PPD, N-acetyl-pphenylenediamine (MAPPD) and N, on -diacetyl-p-phenylenediamine (DAPPD) levels with cardiac manifestations of the poisoned patient. Forty patients completed the diagnosis to have acute poisoning following hair dye ingestion. PPD and its metabolite concentrations did not show any significant correlation with the prevalence of cardiac toxicity and could not predict its occurrence among studied patient ( $\mathrm{p}$-value $>$.05)

Keywords: Hair dye-paraphenylenediamine-cardiac-suicidal

\section{INTRODUCTION}

Paraphenylenediamine PPD is an aromatic amine predominantly found in commercial hair dyes as well as henna. It is highly toxic as it causes severe hypersensitivity reactions. Stone hair dye (SHD) is a cheap traditional black hair dye that is widely used in Upper Egypt (Ragaa et al., 2006; Abdelraheem et al., 2014; Irfan,2001).

Hair dyeing as well as tattoo drawing on body with Henna has has been done for hundreds of years. Lawsonia inemis leaves is the plant from which black henna is extracted (El Nagdy et al., 2020)
Over many centuries, dyeing hair with henna which is derived from the leaves of Lawsonia inermis plant was traditionally used among the Egyptians. PPD is either used alone to draw black tattoo on body or

Hair dye poisoning is highly common in the Eastern world. Accidental and/or suicidal oral ingestion of commercial hair dye has been reported in India, Tunisia, Sudan, Morocco, and Egypt, especially in Upper Egypt. SHD poisoning causes higher mortality than other preparations (Sudulaguntaetal., 2015; AbdelMoeim,2017; Kallal et al.,2005).

PPD is absorbed into the blood after oral intake into through mucosa of the 
gastrointestinal tract; then, it becomes metabolized in the liver into N-mono(MAPPD) and N, $\mathrm{N}^{\prime}$ - diacetylated (DAPPD) metabolites (Nohenek et al.,2015). Tissue damage after PPD ingestions occurs due to increased free radical and oxidative stress that depletes tissue's glutathione (Sirinivas et al., 2010). PPD poisoning has three phases. Phase (1) starts 4-6 hours post-ingestion. It shows burning sensation in the throat and mouth, numbness, intense edema, and persistent vomiting with dehydration (Sudulagunta, 2015; Yagi et al., 1991; Abdulla \& Davidson, 1996). Phase (2) starts 12 hours post-ingestion. It manifested mainly by acute tubular necrosis and renal failure (Sudulagunta et al., 2015). In Phase (3), the patient's clinical condition progresses to multiple organ system failures, and the patient dies (Abdulla \& Davidson, 1996). Cardiac toxicity is a complication of PPD poisoning. It could be manifested by hypotension, different arrhythmia (Dudani et al., 2018). Also, myocarditis and elevated cardiac biomarkers were found (Melli et al., 2005). Oral ingestion of 10 mg PPD can result in extensive myocardial damage with hypotension and lethal lifethreatening arrhythmias. Immediate induction of an appropriate and fast, supportive treatment, including lifesaving tracheostomy, anti-allergic therapy, and forced diuresis, could decrease PPD morbidity and mortality indices. This is because antidote is not more available (Hooff et al.,2014).

The current study aimed to identify the cardiac toxicity of the orally ingested stone hair dye and its relationship to urinary levels of PPD and its metabolites.

\section{PATIENTS \& METHODS}

This prospective cohort single-center study was conducted in Luxor International Hospital from January 2016 to July 2017. Acute SHD poisoning was suspected if a patient has a history of hair dye ingestion. The colored dye was retrieved from the gastric wash, and cervicofacial edema and black urine due to myoglobinuria were present. Cases with a history of mixed poisoning as well as patients with chronic diseases, e.g., myocardial infarction, hypertension were excluded from the study.

On admission to the emergency department, a detailed medical examination is performed, followed by urine and blood sample collection, after those required investigations including creatine kinase-MB (CK-MB), creatine kinase $(\mathrm{KC})$, and lactate dehydrogenase $(\mathrm{LDH})$ and urinary level of PPD and its metabolites.

ECGs with baseline 12-lead were recorded with a paper speed of $25 \mathrm{~mm} / \mathrm{s}$ from each patient. Cardiac toxicity induced by PPD was diagnosed through ECG changes and/or increased cardiac biomarkers (Halliday, 1994).

\section{Reagents and materials}

Kinase (CK), measured by a spectrophotometric assay using LDH Assay Kit (Colorimetric) and Creatine Assay Kit (Colorimetric/Fluorometric) (ab102526)provided by abcam, Inc. Their ranges were between $0.001-10 \mathrm{~mm}$, and 1$100 \mathrm{mU} / \mathrm{ml}$, respectively.

Creatinine kinase-MB (CK-MB) was measured by ELISA technique provided by OxisResearch $^{\mathrm{TM}}$. Levels of $>9 \mathrm{ng} / \mathrm{ml}$ indicated myocardial damage.

Urinary P-phenylenediamine and the detection of its metabolites

Reagent: P-phenylenediamine (PPD) (97\%), 4-amino acetanilide (MAPPD) (98\%), and N,N-P-phenylenebisacetamide (DAPPD) $(98+\%)$ were purchased from Alpha Aesar, Thermofisher, Germany.Internal standard aniline (for synthesis) was purchased from the research lab. Purified water (HPLC grade) was obtained using a direct-Q gradient $8 \mathrm{UV}$ system (Millipore). Dichloromethane, Acetonitril were purchased from Carlo Erba group, Inc. (HPLC grade). Hydrochloric acid, Ammonium solution $25 \%$ were from ADWIC. Potassium dihydrogen phosphate $99 \%$ was purchased 
from Alpha Aesar, Thermofisher, Germany. Sodium hydroxide $97 \%$ was purchased from Alpha Aesar, Thermofisher, Germany.

Instrumentation: HPLC (highperformance liquid chromatography) using an isocratic system formed of a DionexUltiMate 3000 UHPLC; RS pump, auto-sampler, column compartment, and diode array detector. Chromatographic column reversed phase $150 \mathrm{~mm} \times 4.6 \mathrm{~mm}$ Hypersil BDS, C18 particle size 5u kept at $25^{\circ} \mathrm{C}$. The mobile phase was formed of acetonitrile: buffer $(0.01 \mathrm{M})$ potassium dihydrogen phosphate in a ratio of $(20: 80$, $\mathrm{v} / \mathrm{v}), \mathrm{pH}$ was adjusted to 5.0 with $0.1 \mathrm{M}$ sodium hydroxide. The flow rate is 1.0 $\mathrm{mL} / \mathrm{min}$. The UV detector was set to scan from 200 to $800 \mathrm{~nm}$ and had a discrete channel set at $240 \mathrm{~nm}$ (Mohamed et al., 2014). Retention time (Rt) for PPD, MAPPD, DAPPD was 3.96, 5.5, $8.12 \mathrm{~min}$, respectively, and for the anline (IS) 9.17 min. Data were analyzed with the Chromeleon 7 software.

\section{Calibration procedure}

Various Calibration parameters are:

1. Flow rate accuracy $\neg$

2. Injector accuracy $\neg$

3. System Precision $\neg$

4. Wavelength accuracy $\neg$

5. Detector linearity $\neg$

6. Injector linearity $\neg$

7. Gradient Performance Check $\neg$ Flow Rate Accuracy:

a) All the solvent lines were primed with Milli Q water.

b) The flow rate was set to 0.500 $\mathrm{ml} / \mathrm{m}$.

c) Outlet tubing was inserted into a 10 $\mathrm{ml}$ volumetric flask.

d) Stop the stopwatch when the lower meniscus reaches the $10 \mathrm{ml}$ mark on the flask.

e) Record the elapsed time.

f) Time taken to collect the water was $2 \%$ of the actual value.

Injector Accuracy:

a) The pump and detector related to the union. b) the mobile phase was prepared to consist of a mixture of water and Methanol $(70: 30 \mathrm{v} / \mathrm{v})$

c) flow inlet rate was set of $0.5 \mathrm{ml} / \mathrm{m}$ and a run time of $1 \mathrm{~m}$.

d) the column temperature was set at $25 \pm 2{ }^{\circ} \mathrm{C}$.

e) The standard HPLC vial was filled to $2 / 3$ rd with Milli-Q water. The vial was appropriately sealed with a cap.

f) The vial was weighed, and the weight was recorded as W1 grams.

g) the vial was placed in the chromatographic system and performed

h) $50 \mu \mathrm{l}$ volume was injected from this vial.

i) The vial was weighed again and note the weigh after the injections as W2 grams.

The mean injected volume was50ul

Wavelength Accuracy:

Procedure: Create and instrument method with a wavelength in $\mathrm{nm}$ and inject blank, followed by Standard preparation and note down the height or absorbance. The maximum absorbance should be $\pm 2 \mathrm{~nm}$.

PDA Detector Accuracy: 3D mode was selected and set the wavelength range as $200-400 \mathrm{~nm} . \quad 20 \mu \mathrm{l}$ of standard preparation was injected once into the chromatographic system.

Column Oven Temperature Accuracy:

It was evaluated with a calibrated digital thermometer at $30^{\circ} \mathrm{C}$ and $60^{\circ} \mathrm{C}$. the thermometer probe was placed in the column oven and set the column oven temperature at $30^{\circ} \mathrm{C}$. after the temperature stabilized, the temperature displayed was recorded on the thermometer. Acceptance criteria: The resulting oven temperature from the thermometer display was within $\pm 2^{\circ} \mathrm{C}$ of the set temperature.

Preparation of standard and quality control samples: the stock solutions were prepared using 1000 micrograms of analytical standard added to $10 \mathrm{ml}$ water. The preparation of a working standard solution was done by diluting the stock solution with water daily. Blank Serum 
samples and blank urine were spiked to get standard calibration solutions in the range of $0.015-2 \mu \mathrm{g} / \mathrm{mL}$. Quality control (QC) samples of $0.05 \mu \mathrm{g} / \mathrm{mL}$ (low QC), 0.25 $\mu \mathrm{g} / \mathrm{mL}$ (medium QC), and $1 \mu \mathrm{g} / \mathrm{mL}$ (high QC) were also prepared.1ml of solution contains $1 \mathrm{mg}$ of Paraphenylenediamine, monoacetyl PPD, diacetyl PPD. The internal standard used was aniline, and it was dissolved in water.

Injector Linearity: Standard Preparation: Accurately weigh and transfer about $60 \mathrm{mg}$ of the standard into a $100 \mathrm{ml}$ volumetric flask. Dissolve and dilute to the volume with the mobile phase. Transfer $10 \mathrm{ml}$ of Standard Preparation into a $100 \mathrm{ml}$ volumetric flask and dilute to the volume with the mobile phase

Column Oven Temperature Accuracy: It is evaluated with a calibrated digital thermometer at $30^{\circ} \mathrm{Cand} 60^{\circ} \mathrm{C}$. Place the thermometer probe in the column oven and set the column oven temperature at $30^{\circ} \mathrm{C}$. Wait till the temperature stabilizes. Record the temperature displayed on the thermometer. Similarly, it performs the column oven temperature accuracy test at $60^{\circ} \mathrm{C}$. Acceptance criteria: The resulting oven temperature from the thermometer display should be within $\pm 2{ }^{\circ} \mathrm{C}$ of the set temperature.

Sample Pretreatment: urine samples were prepared by adding $0.5 \mathrm{ml}$ of urine hydrolyzed using $0.5 \mathrm{ml}, 12 \mathrm{~N} \mathrm{HCl}$ for one $\mathrm{h}$ at $100^{\circ} \mathrm{C}$, and alkalized with conc. Ammonium hydroxide (Mohamed et al., 2014).
Sample preparation (liquid-liquid extraction): Liquid/liquid extraction (LLE) was done by adding $0.25 \mathrm{~mL}$ hydrolyzed urine and $1.0 \mathrm{~mL}$ blood to 100 $\mu \mathrm{L}$ of $100 \mu \mathrm{g} / \mathrm{mL}$ aniline (IS) to each of the blood and urine samples. After that, $0.25 \mathrm{~mL}$ of conc. Ammonium hydroxide $(33 \%)$ and $6.0 \mathrm{~mL}$ of dichloromethane were added. The tubes were then vortexed at the rate of $40 \mathrm{rpm}$ for 20 -minutes, then they were centrifuged at $3200 \mathrm{rpm}$ for 5minutes. The organic layer was removed and transferred to a second $10-\mathrm{mL}$ polypropylene tube containing $0.5 \mathrm{~mL}$ of 1.0 $\mathrm{M}$ hydrochloric acid. The tubes were then vortex mixed for 5-minutes and centrifuged at $3200 \mathrm{rpm}$ for 5-minutes. The organic layer was removed to the remaining aqueous solution, $150 \mu \mathrm{L}$ of conc. Ammonium hydroxide and $2.0 \mathrm{~mL}$ of dichloromethane were added. The tubes were then centrifuged at $3200 \mathrm{rpm}$ for 5minutes. The organic layer was transferred to 5-mL glass tubes and evaporated to dryness. The dried extracts were reconstituted in the mobile phase, vortex mixed for 30-seconds and then injected into the HPLC system with an injection volume of $100 \mathrm{u}$. The flow rate is 1.0 $\mathrm{mL} / \mathrm{min}$. The UV detector was set to scan from 200 to $800 \mathrm{~nm}$ and had a discrete channel set at $240 \mathrm{~nm}$ (Mohamed et al., 2014). Retention time (Rt) for PPD, MAPPD, DAPPD was 3.96, 5.5, 8.12 min, respectively, and for the anline (IS) 9.171 min. Data were analyzed with the Chromeleon 7 software. (Mohamed et al., 2014).

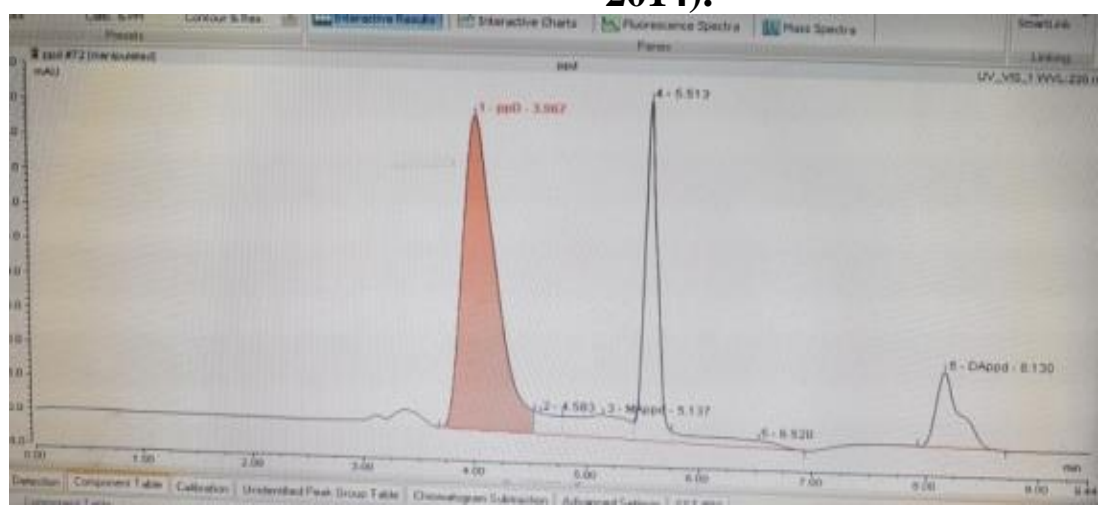

Figure (1): chromatogram of spiked urine sample containing $87.7 \mathrm{Ug} / \mathrm{ml}$ of ppd,mappd,dappd as an external standard, concentrations 10ul. 


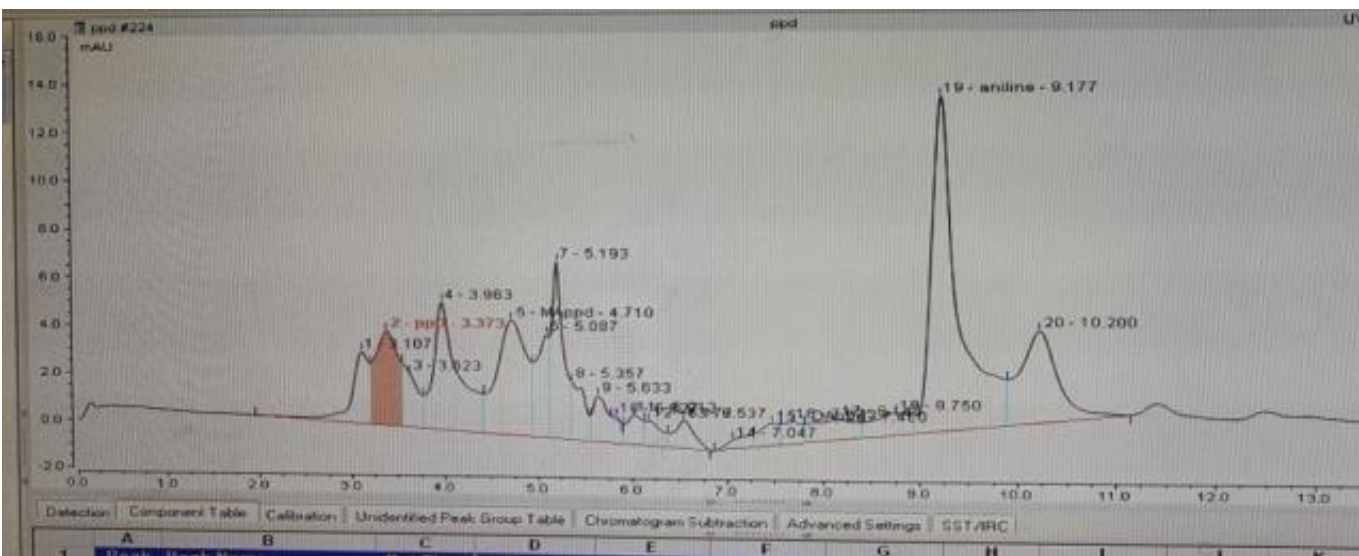

Figure (2): chromatogram of toxic urine case containin0.8939 ug/ml of PPD, $18.6315 \mathrm{ug} / \mathrm{ml}$, MAPPD, $27.65 \mathrm{ug} / \mathrm{ml}$ DAPD and 20ul ANLINE as internal standard.

The validation of the analytical method was as follow:

Linearity: The presented analytical procedure proved to be linear (squared correlation coefficient $\mathrm{r} 2=0.987, \mathrm{n}=5$ for $\mathrm{ppd}, \mathrm{r}^{2}=0.993 \mathrm{n}=5$ for MAPPD and $r^{2}=0.998 n=5$ for DAPPD.

Quality control samples: Blank samples with a series of concentrations $0.03,1, \quad 10, \quad 50,100,200,30,1000 \quad \mathrm{ug} / \mathrm{ml}$ ) standard PPD, MAPPD, DAPPD were prepared to investigate the linearity, LOD, and LOQ. Range 0.03-1000ug/mL. Limit of detection (LOD) and limit of quantification (LOQ): The LOD is the lowest amount of the analyte that can be detected. $\mathrm{LOD}=3.3{ }^{*} \mathrm{St}$ deviations/slope; LOD $=0.03135 \mathrm{ug} / \mathrm{ml}$.LOQ is the lowest concentration of the analyte that can be detected.LOQ $=10 * \mathrm{St}$ deviation/slope $\mathrm{LOQ}=0.095 \mathrm{ug} / \mathrm{ml}$

Accuracy (extraction recovery): The recovery was evaluated with three replicates of the QC sample, formed of $1 \mathrm{ml}$ blank added to an external standard (with three different concentrations) and 10ul of internal standard anline. Concentrations of external standard were $0.03 \mathrm{ug} / \mathrm{mL}$, $50 \mathrm{ug} / \mathrm{mL}$ and $1000 . \mathrm{ug} / \mathrm{mL}$ (low, medium, and high concentrations). The extraction recoveries were calculated as the percentage of $\mathrm{A}_{\mathrm{E} . \mathrm{S} / \mathrm{A}_{\mathrm{I} . S}}$ (ratio of the area between external and internal standard) value extracted from samples over those obtained by direct determination of the standard solutions (and internal standard) at the same concentration level. The recovery of PPD, MAPPD, and DAPPD for all the 3 QC levels were more than $80 \%$.

Precision (relative standard deviation): for each sample, three injections were done, and the mean value was calculated.

The relative standard deviation of High (497.37ug), medium (138.32ug), and low (0.066.ug) concentrations were $1.16 \%$, $1.23 \%$, and $5.11 \%$.

\section{Statistical methods}

Data were analyzed using SPSS ( Statistics version 23 (IBM@ Corp., Armonk, NY, USA) and MedCalc(C) version 15.8 (MedCalc@ Software bvba, Ostend, Belgium). Qualitative data were expressed as count (\%) and compared in different groups using the chi-square test, while quantitative data was tested using the student t-test. Correlations were tested using the Spearman rank correlation. Pvalue $\leq 0.05$ was considered significant. 


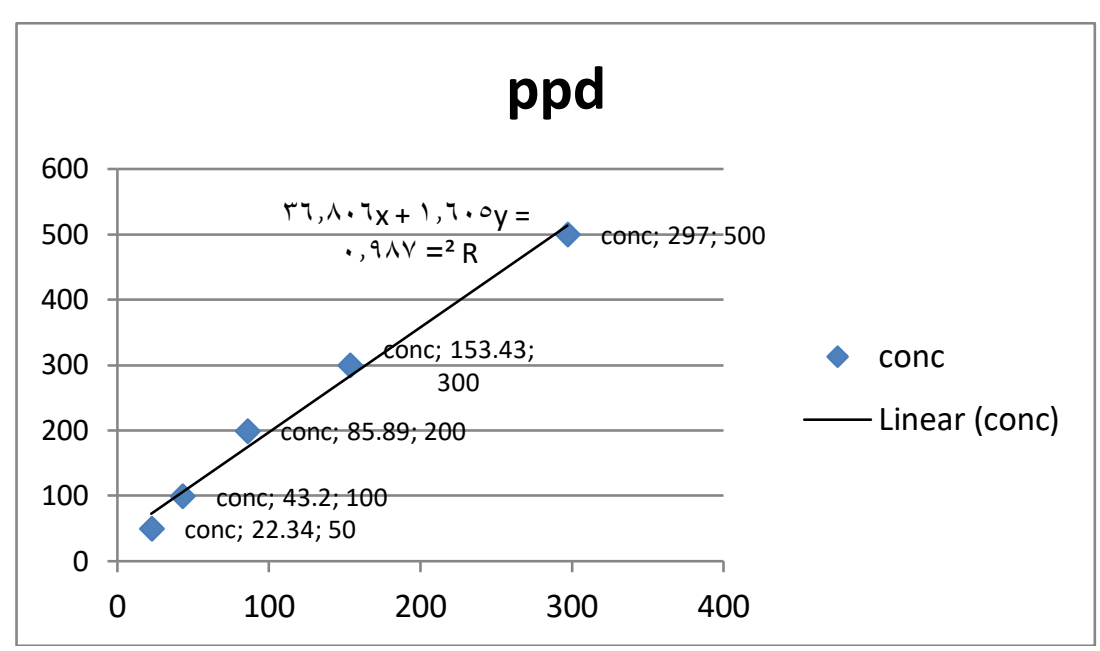

Figure (3): linear regression of the calibration curve of four concentrations of PPD

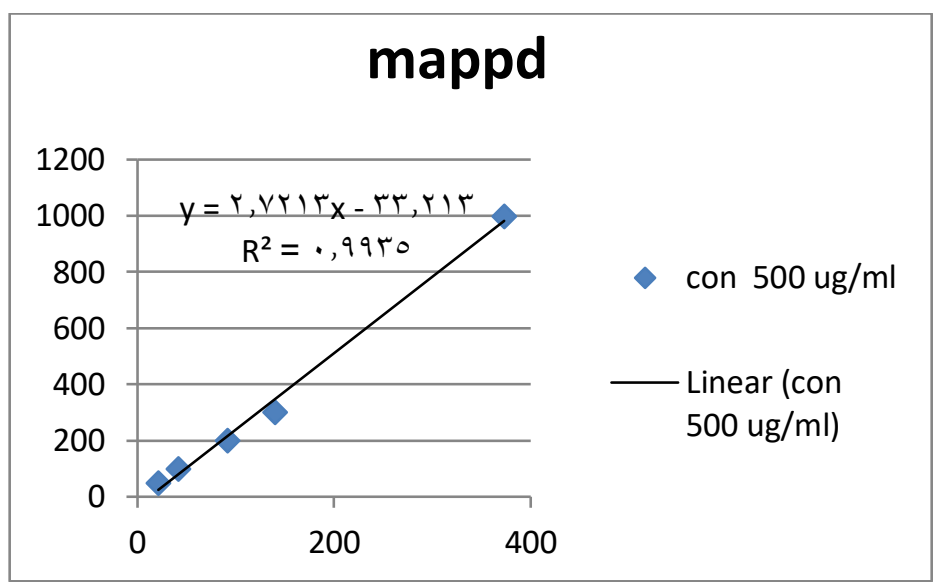

Figure (4): linear regression of the calibration curve of five concentrations of MAPPD.

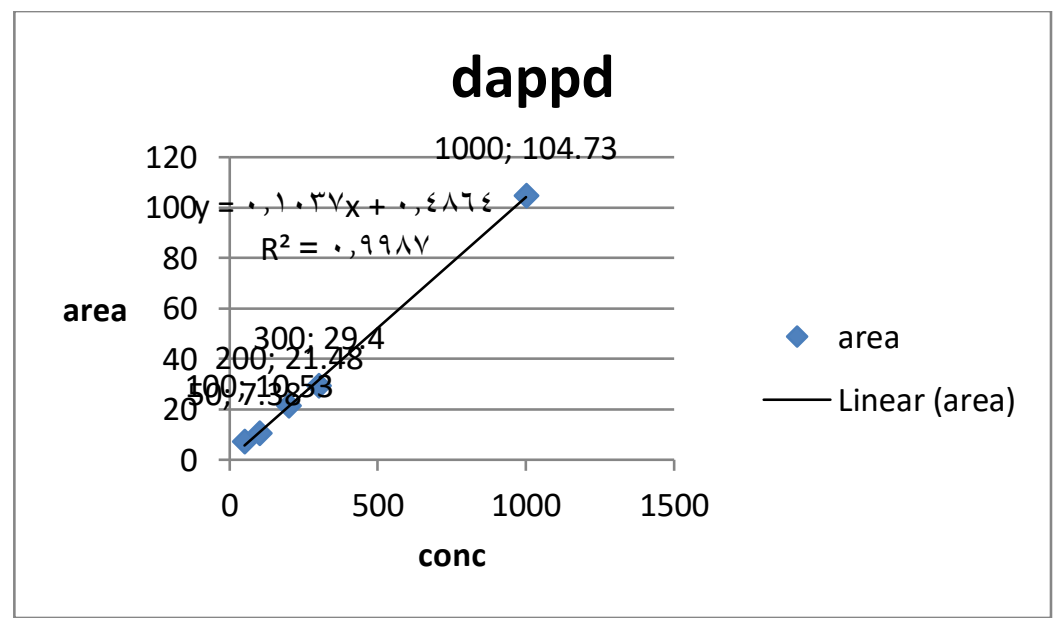

Figure (5): linear regression of the calibration curve of five concentrations of DAPPD. 


\section{RESULTS}

Forty patients from the Upper Egypt region were included in the study. $75 \%$ of them were females with a mean age of 25 years. Most of the cases were suicidal poisoning $(72.5 \%)$.

On admission, the mean values of heart rate, systolic and diastolic blood pressure were $129 \mathrm{beat} / \mathrm{min}, 122 \mathrm{mmHg}$, and $72 \mathrm{mmHg}$, respectively.
Hypotension was recorded in 4 patients (10\%), and ECG showed different patterns of arrhythmia in 24 patients; $7.5 \%$ of them had sinus tachycardia, $22.5 \%$ developed nonspecific ischemic changes in the form of diffuse bundle branch block, ST-segment elevation or depression, and T wave inversion, $15 \%$ had atrial and ventricular premature complexes, and 15 $\%$ developed ventricular tachycardia.

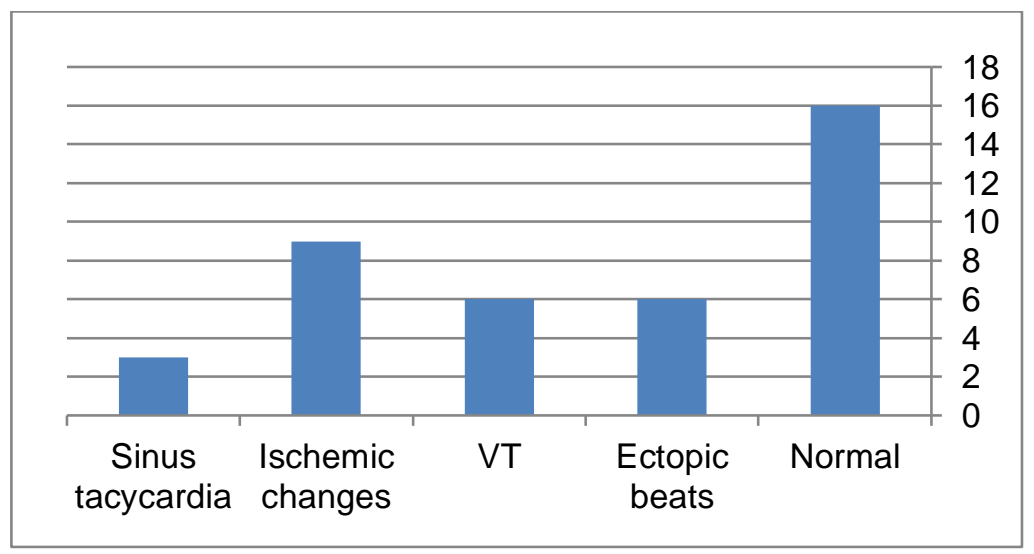

Figure (6): ECG changes on admission for studied patients

On admission, LDH and CK levels were increased with mean values 5035 and 2224U/L, respectively. CK-MB was increased in 27 patients $(67.5 \%)$ with a mean value of $768 \mathrm{U} / \mathrm{L}$. On admission, urinary PPD and its main metabolites, MAPPD and DAPPD, were detected in 38 patients $(95 \%)$, where their mean values were 231.8, 736.7, and $11776.8 \mu \mathrm{g} / \mathrm{ml}$, respectively. Forty-eight hours after treatment, urinary PPD, MAPPD, and DAPPD mean values were decreased to reach 22.8, 38.2, and $1586.8 \mu \mathrm{g} / \mathrm{ml}$, respectively.

Table (1): levels of LDH, CK, CK-MB, PPD MAPPD, and DAPPD levels on admission and 48 hours after treatment

\begin{tabular}{|l|l|l|l|l|}
\hline & Mean & SD & Minimum & Maximum \\
\hline LDH & 5035 & 5990 & 305 & 21000 \\
\hline CK & 2224 & $\mathbf{2 6 3 3}$ & $\mathbf{4 0}$ & $\mathbf{1 0 0 0 0}$ \\
\cline { 2 - 5 } & 1882 & $\mathbf{1 5 0 3}$ & $\mathbf{1 0 0 0}$ & $\mathbf{5 1 7 8}$ \\
\hline \multirow{2}{*}{ CK-MB } & 768 in 29 cases & 801 & 10 & 3000 \\
\cline { 2 - 5 } & 338 in 10 cases & 311 & 31 & 950 \\
\hline \multirow{3}{*}{ PPD } & $\mathbf{2 3 1 . 8}$ & $\mathbf{4 6 8 . 8}$ & $\mathbf{0 . 1}$ & $\mathbf{2 5 7 0 . 0}$ \\
\cline { 2 - 5 } & $\mathbf{2 2 . 8}$ & $\mathbf{8 8 . 6}$ & $\mathbf{0 . 1}$ & $\mathbf{4 5 9 . 0}$ \\
\hline \multirow{3}{*}{ MAPPD } & $\mathbf{7 3 6 . 7}$ & $\mathbf{1 9 6 2 . 0}$ & - & $\mathbf{1 1 7 0 0 . 0}$ \\
\cline { 2 - 5 } & $\mathbf{3 8 . 2}$ & $\mathbf{7 9 . 5}$ & 0.4 & $\mathbf{3 0 1 . 6}$ \\
\hline \multirow{2}{*}{ DAPPD } & $\mathbf{1 1 7 7 6 . 8}$ & $\mathbf{2 2 6 2 8 . 0}$ & - & $\mathbf{8 6 1 3 5 . 5}$ \\
\cline { 2 - 5 } & $\mathbf{1 5 8 6 . 8}$ & $\mathbf{6 9 7 5 . 3}$ & - & $\mathbf{3 6 9 1 3 . 0}$ \\
\hline
\end{tabular}




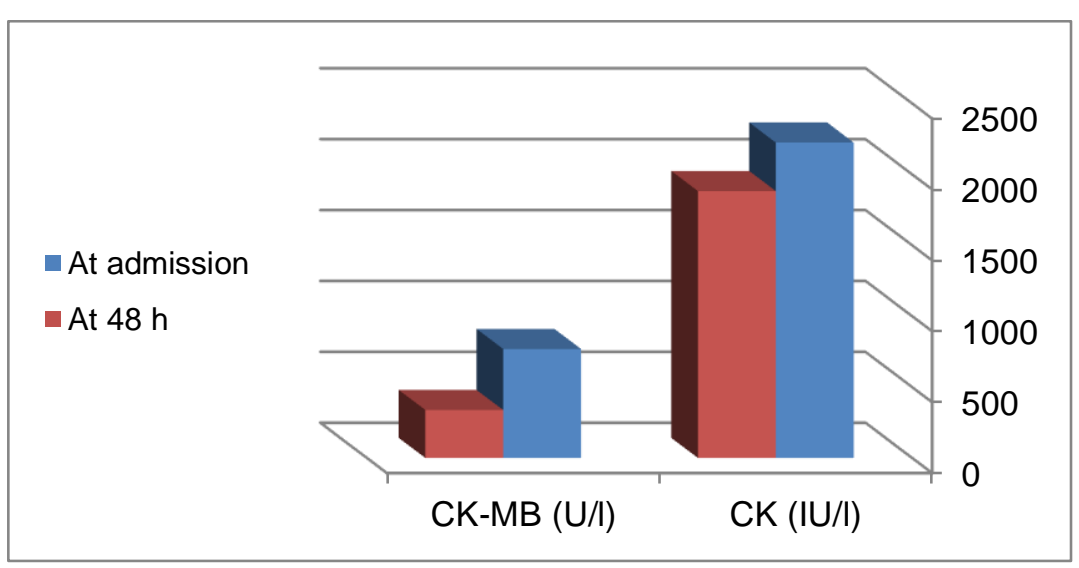

Figure (7): The mean level of CK and CK-MB at different times.

According to ECG changes and CKMB, 27 patients had been diagnosed with PPD induced cardiac toxicity. Twenty-six patients showed multi-organ affection in variable range, where 5 cases $(19.2 \%)$ have three organs affected, 7 cases $(26.9 \%)$ have four organs affected, 9 cases $(34.6 \%)$ have five organs affected, and 4 cases $(15.4 \%)$ have 6organs affected. Unfortunately, urinary PPD and its metabolite concentrations did not show any significant correlation with the prevalence of cardiac toxicity and could not predict its occurrence among studied patient (pvalue $>.05$ )

\section{DISCUSSION}

The total number of cases enrolled in this study was 40 out of the $30(75 \%)$ were females, and $10(25 \%)$ were males. This was nearly the same number of patients studied by Mohamed KM et al. (2014) and Abdel-Maaboud et al. (2008) they reported number of females in cases of poisoning in Upper Egypt was higher than that of males. This occurred due to the frequent use of cosmetics by females and the cheapness and availability of the stone dye. The studies of AyoubFilaliet al. (2006), and Ramulu et al. (2016) showed a female preponderance with $77 \%, 94.7 \%$, $89 \%, 93.3 \%$. and $80.64 \%$ respectively.

In the present study, most patients were age 18- 28 years old (mean age was $25 \pm 11$ ). Many researchers agreed with our results in their studied patients as Ramulu $P$ et al. (2016) and AyoubFilaliet al.
(2006), And Qasim AP et al. reported that the prevalence of self-harm by using PPD was more in the age range of 11-30 years.

Committing suicide occurs mainly due to psychological problems as well as social problems like failure in the exams. Concerning the manner of death, the intent of ingestion in our study was suicidal in $72.5 \%$, accidental $10 \%$, and suspected PPD poisoning in $17.5 \%$. All cases ingested hair dye by the oral route, and all of them consumed unbranded stone hair dye. Regarding the reason of poisoning, suicidal intention was identified in the studies carried by Mohamed KM et al. (2014), Nisar Khan et al. (2015), Rawat $R$ et al. (2016) Jain et al. (2011), Abdel-Moneim A (2017) and Kakkar et al. (2016) to present $91.7 \%, 73.7 \%, 86.7 \%, 94.74 \%$, $100 \%, 97.84 \%, \quad 91.7 \%$ and $95.7 \%$ respectively. Rawat $R$ et al. (2016) reported that the psychological evaluation was normal in all these patients. This indicates that most suicidal attempts were impulsively precipitated by either scolding from parents, family quarrels, or socioeconomic failure.

Hair dye is a potent cardiotoxin, and its ingestion leads to myocardial damage. Owing to myocardial damage, there is a release of cardiac-specific markers such as Trop T, Trop I, and CPK-MB. In this study, $60 \%$ of patients had ECG changes, $75 \%$ of patients show elevated serum level of CPK-MB level up to 3000 U/l. Our results were in accordance with the results of Rawat $\mathbf{R}$ et al. (2016)', and Ramulu $\mathbf{P}$ 
et al. (2016) concluded that cardiac arrhythmias were documented in $40 \%$, $11.53 \%$, and $38 \%$, respectively.

The cause of myocardial damage might state by Senthilkumaran et al., who noted that the incidence was bound to patients' susceptibility to PPD, apart from the amount of dye ingested. However, oral ingestion of PPD in doses $>10 \mathrm{~g}$ caused myocardial infarction, especially with the consumption of unbranded stone hair dyes. In our study, we reported one case of myocardial infarction, which also recorded by Brahmi et al. (2006) and Jatav et al. (2008) reported a case of myocarditis with myocardial infarction caused by consumption of PPD where they confirmed it by angiography, that showed septoapical hypokinesia due to spasm of the left anterior descending coronary artery.

About $10 \%$ of our studied patients developed shock due to myocarditis, which was a fatal complication. Vasopressors and inotropes are needed in $10 \%$ and $7.5 \%$, respectively. Kallel et al. (2005) recorded that shock occurred in $26.3 \%$ of patients, which necessitated vasopressors. It is explained by myocardial rhabdomyolysis and hypovolemia or result differed from that recorded by Kallel et al. (2005) that might duo to his study was retrospective and only on 19 patients.

In our study, the mean urinary level of PPD, MAPPD, and DAPPD showed a gradual decrease level until 48 hours from admission. We recorded that the major metabolite excreted via the urine was diacetyl-PPD which, in accordance with Mohamed KM et al., urine samples were hydrolyzed using hydrochloric acid before extraction due to the presence of $\mathrm{N}, \mathrm{N}$ diacetyl-PPD (the main metabolite) which is present in high concentration levels in urine samples. The urine of five volunteers who had used a commercial hair dye preparation containing 1.1-1.6 $\mathrm{g}$ of PPD was examined. The major metabolite detected by this technique is $\mathrm{N}$; N-diacetylPPD. The diacetyl derivative of the PPD was found to be excreted in the urine for
$42 \mathrm{~h}$ after dyeing, the average amount being $0.14 \mathrm{mg} / \mathrm{ml}$ per person.

Hueber-Becker et al. reported that the total excretion was $0.54 \% \pm 0.25 \%$ of the applied dose. The majority $(86 \%)$ of absorbed radioactivity was excreted within $24 \mathrm{~h}$ after application. Nohyneket al and Goetz et al. revealed that the majority of $80-95 \%$ of the PPD metabolites excreted via the urine consisted of monoacetyl-PPD and diacetyl-PPD.

In contrast to our study, we agreed that the major metabolite excreted via the urine was diacetyl-PPD. And we agreed with SCCP that after 48hours, most PPD and its metabolites were eliminated. We disagreed with them in amounts of exerted PPD and its metabolites as their studies all after topical hair dye application. After PPD ingestion, the primary metabolism will be more influenced by NAT2, which is in the guts and liver. We couldn't determine the percentage of the PPD, and its metabolites excreted via the urine, as there was no definite data about the amount ingested.

\section{REFERENCES}

Abdel-Maaboud R. M., Kamalat A. A., Ahmed S. M., Aly N. S., and Aly H. A., (2008) "A five year retrospective study of poisoning cases investigated by the Forensic 15 Chemical Laboratory in Upper Egypt". Assiut Medical Journal, May, Vol. 32, No. 2.

Abdel-Moneim A (2017) Acute Toxicity by Hair Dye in Upper Egypt. Int $\mathbf{J}$ Forensic SciPathol. 5 (1):305-311.

Abdelraheem MB, Elbushra M, Ali el-T, Ellidir RA, BusharaAI,et al. (2014) Filicide and suicide in a family by para-phenylenediamine poisoning: a mother who committed suicide and poisoned her four children of which one died. ToxicolInd Health 30: 679682.

Abdulla KA. And Davidson NM." (1996). A woman who collapsed after painting her soles "Lancet 1996; 348358. 
AnkitaKakkar, Alok Kumar, Sushil Kumar, and Archana Verma (2016). Hair dye poisoning in India. European Journal of Forensic Sciences Sci, 2016, (3)

Brahmi N, Kouraichi N, Blel Y, Mourali $S$, Thabet $H$, Mechmeche $R$, Amamou M. Acute myocarditis and myocardial infarction induced by Paraphenylenediamine poisoning. Interest of angiocoronarography. Int J Cardiol. 2006; 113 (3):E93-5.

Dudani M, Jatav O, Agrawal J (2018): clinical features and complication following paraphenylenediamine poisoning: a prospective clinical study .Indian Journal of applied research. (8):79-80.

Filali A, Semlali I, Ottaviano V,Soulyamani R, Furnari C, Corradini D (2006). A retrospective study of acute systemic poisoning of para-phenylenediamine

(occidentaltakawt) in Morocco. Afr $\mathbf{J}$ TradCAM.3:142-9.

Giese, J. E., Miller, J. A., and Baumann, C. A. (1945). Cancer Research, 5. 337.

Goetz N, Lasserre P, Bore $P$ et al. (1988) Percutaneous absorption of $p$ phenylenediamine during an actual hair dyeing procedure (1988). Int $\mathrm{J}$ CosmetSci; 10: 63-73.

Halliday, J. (1994). Principles of Cardiac toxicology.

Cardiovascular Research, 28 (4), 578-579.

Hooff M (2014). Analytical Investigations of Toxic p-Phenylenediamine (PPD) Levels in Clinical Urine Samples with Special Focus on MALDI-MS/MS.

Hueber-Becker F, Nohynek GJ, Meuling WJ (2004). Human systemic exposure to a [14C]-para-phenylenediaminecontaining oxidative hair dye and correlation with in vitro percutaneous absorption in human or pig skin. Food ChemToxicol; 42: 1227-36.

Irfan H. "Dangerous dyes." http://www.islamonline.net/english/sci ence/2001/07/artocle 6.shtml.
Jain P. K., Agarwal N, Sharma A. K. and Akhtar A., (2011), Prospective study of ingestion hair dye poisoning in Northern India (Prohina) Journal of Clinical Medicine and Research Vol. 3 (1) Pp. 9-19 January.

Jatav OP, Jeelima Singh, Gupta RJ, Tailor ML (2008). Myocardial damage in hair dye poisoning. J. Assoc. Physicians India, 56: 463- 464.

Kallel H., Chelly H. Dammak H., Bahloul M., Ksibi H., Hamida C.B., Chaari A., Rekik V., Debore M. E. and Bouaziz M (2005). "Clinical manifestation of systemic paraphenylenediamine intoxication." J. Nephrol, 18:308-311

Khan N, Khan H, Khan N, Ahmad I, Shah F, Rahman AU, Mahsud I. Clinical presentation and outcome of patients with para-phenylenediamine (kala-pathar) poisoning. Gomal J Med Sci 2015; 14: 3-6.

Melli, G., Chaudhry, V., and Cornblath, D. R. (2005). Rhabdomyolysis: an evaluation of 475 hospitalized patients. Medicine 84, 377-385.

Mohamed KM, Hilal MA, Nady S. Aly (2014) Fatal Intoxications with ParaPhenylenediamine in Upper Egypt. Int J Forensic SciPathol. 2 (3), 19-23.

Nohynek GJ, Skare JA, Meuling WJ et al. (2004). Urinary acetylated metabolites and $\mathrm{N}$-acetyltransferase- 2 genotype in human subjects treated with a para-phenylenediaminecontaining oxidative hair dye). Food ChemToxicol; 42: 1885-91.

Nohynek GJ, Skare JA, Meuling WJ, Wehmeyer KR, de Bie AT, et al. (2015) Human systemic exposure to paraphenylenediamine-containing oxidative hair dyes: Absorption, kinetics, metabolism, excretion and safety assessment. Food ChemToxicol 81: 71-80.

Qasim AP, Ali MA, Baig A, Moazzam MS (2016)Emerging Trend of Self Harm by 'Kala Pathar' Hair Dye (Paraphenylenediamine): An 
Epidemiological Study. APMC;10 (1):26-30.

Ragaa M. M., Madeha M. M. Makhlof and Manal M.S.El-Meligy, (2006), "Systemic effects of ingestion of hair dye: An experimental study "The 2nd Int. Conf. for Develop. And the Env. In Arab world, March 21, 23.

Ramulu P, Rao PA, Swaroop KK, Marx PK, Devi CVR (2016). A prospective study on clinical profile and incidence of acute kidney injury due to hair dye poisoning. Int J Res Med Sci; 4: 5277 82.

Rawat R, Kumar M, Singh PS, Kumar G, VermaV (2016). Study of hair dye poisoning and its outcome in tertiary care rural institute. Int J Res Med Sci 2016; 4:3240-4.

Ron D,Taitelman U, Michaelson M,BarJosephG,BurszteinS,Better (1984) OS. Prevention of acute renal failure in traumatic rhabdomyolysis Arch Intern Me; 144:277-80.

Samah, A. El-Nagdy, Rasha L. Etewa ,Eman M. Mohamed , Yara, M. ElFakharany (2020). Possible toxicological effects associated with chronic dermal exposure to paraphenylenediamine (ppd) on pancreas of adult male albino rats. Egypt J.
Forensic Sci. Appli. Toxicol. Vol 20 (3):77-78.

Senthilkumaran

S, ThirumalaikolundusubramanianP (2015). Acute hair dye poisoning: Lurking dangers. J Mahatma Gandhi Inst Med Sci;20:33-7.

Skare JA, Hewitt NJ, Doyle E, Powrie R, Elcombe C (2009) Metabolite screening of aromatic amine hair dyes using in vitro hepatic models. Xenobiotica 39: 811-825

Srinivas Sutrapu, Jagadeeshwar K, Nagulu M, Vidyasagar (2010). J Oxidative Stress and Antioxidant Status in Hair Dye Poisoning. International Journal of Pharmacognosy and Phytochemical Research 3;1:1-5.

Sudulagunta SR, Gonivada J, Sodalagunta MB and NoroozpourZ (2015). Fatal Hair Dye Poisoning. SM J Case Rep; 1 (2):1008

Suliman SM, Homeida M, AboudOI (1983). Paraphenyl-Isnediamine induced acute tubular necrosis following hair dye ingestion. Hum Toxicol; $2: 633$

Yagi H., el Hind A. M. and Khalil S.I. (1991) "Acute poisoning from hair dye." East Afr Med J. Jun; 6 
الكثف عن مادة بارافينيلين ديامين (صبغة الثعر) ومشتقاته فى الام و البول باستخدام تقتية اتثل بـى

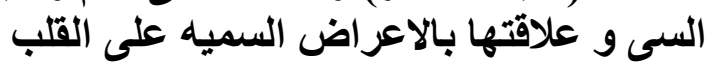

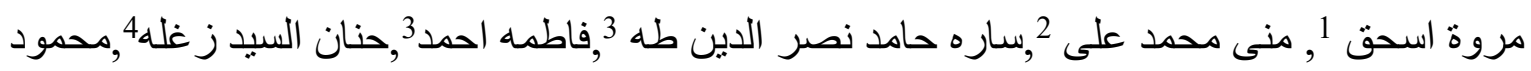

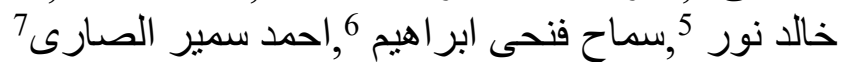

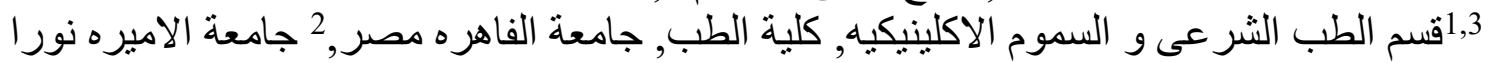

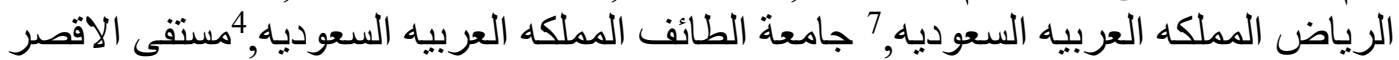
العام 5,6,8,قسم طب الحالات الحرجه جامعة القاهره

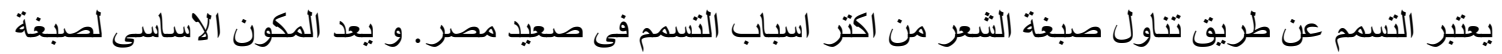

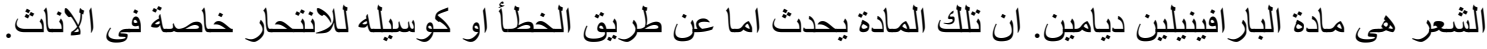

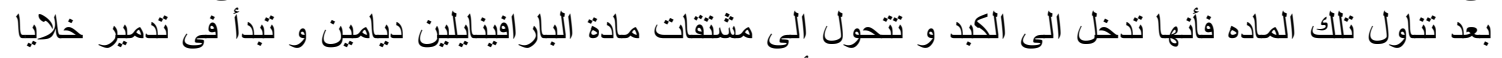

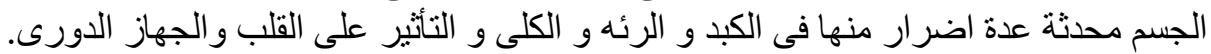

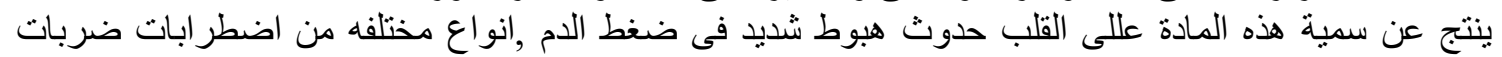

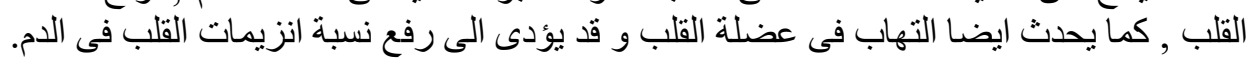

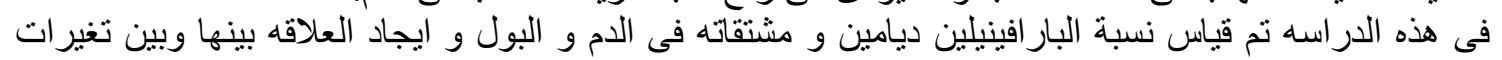

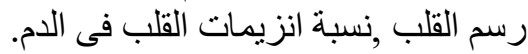

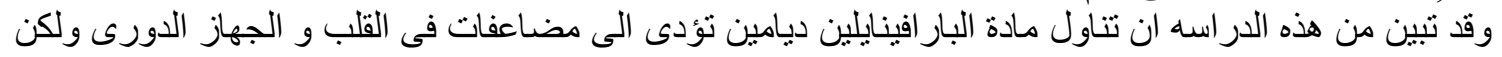

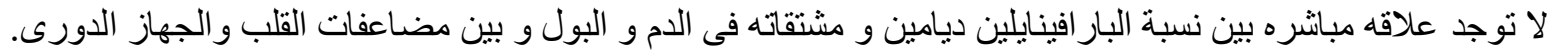

